\title{
Simulations of the Penetration of 6061-T6511 Aluminum Targets by Spherical-Nosed VAR 4340 Steel Projectiles
}

\author{
Thomas L. Warren and Mazen R. Tabbara
}

Sandia National Laboratories Albuquerque, NM 87185-0315

\begin{abstract}
In certain penetration events it is proposed that the primary mode of deformation of the target can be approximated by known analytical expressions. In the context of an analysis code, this approximation eliminates the need for discretizing the target as well as the need for a contact algorithm. Thus, this method substantially reduces the computer time and memory requirements. In this paper a forcing function which is derived from a spherical-cavity expansion (SCE) analysis has been implemented in a transient dynamic finite element code. This implementation is capable of computing the structural and component responses of a projectile due to a three dimensional penetration event. Simulations are presented for 7.11-mm-diameter, 74.7-mm-long, spherical-nose, vacuumarc-remelted (VAR) 4340 steel projectiles that penetrate 6061-T6511 aluminum targets. Final projectile configurations obtained from the simulations are compared with post-test radiographs obtained from the corresponding experiments. It is shown that the simulations accurately predict the permanent projectile deformation for three dimensional loadings due to incident pitch and yaw over a wide range of striking velocities.
\end{abstract}




\section{DISCLAIMER}

This report was prepared as an account of work sponsored by an agency of the United States Government. Neither the United States Government nor any agency thereof, nor any of their employees, make any warranty, express or implied, or assumes any legal liability or responsibility for the accuracy, completeness, or usefulness of any information, apparatus, product, or process disclosed, or represents that its use would not infringe privately owned rights. Reference herein to any specific commercial product, process, or service by trade name, trademark, manufacturer, or otherwise does not necessarily constitute or imply its endorsement, recommendation, or favoring by the United States Government or any agency thereof. The views and opinions of authors expressed herein do not necessarily state or reflect those of the United States Government or any agency thereof. 


\section{DISCLAIMER}

Portions of this document may be illegible in electronic image products. Images are produced from the best available original document. 


\section{Introduction}

Computational modeling of penetration and perforation remains to be an active field of research. A literature search on this topic reveals numerous recent publications that propose new methods or improve existing ones. There has been considerable effort and progress in the development of various codes (based on different representations of the conservation laws for a continuum: Lagrangian, Eulerian, Arbitrary Lagrangian-Eulerian, etc.) that serve as powerful and versatile computational tools which are routinely used to solve complex problems. However, at present, the time required to complete a single penetration run is still excessive and prohibits any prospect for streamlining the penetration analysis for use in an overall design tool that would permit numerous simulations

In cases where the deformation mode of the target can be captured (to first order) by a known analytical model and where the primary interest is in the structural response of the projectile, the penetration analysis can then be reduced to modeling the projectile by itself. The target is replaced by a known forcing function that approximates its resistance. This eliminates the need for discretizing the target as well as the need for a contact algorithm, which reduces the computer time and memory requirements. Furthermore, this method also avoids the problems due to excessive mesh distortion associated with Lagrangian formulations as discussed by Camacho and Ortiz (1997).

Analytical methods for penetration mechanics began with the work of Bishop, Hill, and Mott (1945). They developed equations for the quasi-static expansion of cylindrical and spherical cavities and used these equations to estimate forces on conical nose punches pushed slowly into metal targets. Later, Goodier (1965) developed a model to predict the penetration depth of rigid spheres launched into metal targets. That penetration model included target inertial effects, so Goodier (1965) approximated the target response by results from the dynamic, spherically symmetric, cavity-expansion equations for an incompressible target material derived by Hill (1948) and discussed by Hill (1950) and Hopkins (1960). More recently, Forrestal et al. (1988), Forrestal et al. (1991), and Forrestal et al. (1995), and Warren and Forrestal (1998) developed spherical cavityexpansion penetration models for rigid projectiles that penetrate ductile metal targets. They developed closed-form expressions for the depth of penetration of rigid projectiles with different nose shapes and demonstrated good agreement with experimental results. The same concept is applied here, but in the context of a three dimensional finite element code. A forcing function based on the dynamic expansion of a spherical cavity has been implemented by Warren and Tabbara (1997) in the Sandia developed explicit transient 
dynamic finite element code PRONTO 3D (Taylor and Flanagan, 1989) and can be utilized by analysts who have access to this computer code. This implementation is capable of handling a full three dimensional penetration event which includes: oblique impact, nonzero angle of attack, nonlinear deformations of the projectile, response of components internal to the projectile, etc. The accuracy of this method depends on how well the forcing function approximates the actual situation; however, in many cases the SCE method (which is derived on the basis of an unbounded medium) does provide a good approximation for events where the free surface effects are minimal. Thus, this implementation is most accurate for cases of deep penetration.

Similar methods have also been applied with some success using cavity expansion forcing functions with beam elements in the general purpose finite element code ABAQUS implicit (Hibbitt, Karlsson, and Sorensen, Inc., 1989) by Longcope (1991) and Longcope (1996), and using empirical forcing functions with shell elements in ABAQUS implicit by Adley and Moxley (1996), with shell elements in ABAQUS explicit by Duffey and Macek (1997), and also with tetrahedron, brick, and shell elements in EPIC 97 (Johnson et al., 1997).

In this paper the method implemented by Warren and Tabbara (1997) in the PRONTO 3D finite element code is validated by comparing final projectile configurations obtained from simulations with post-test radiographs obtained from corresponding experiments done by Forrestal and Piekutowski (1998). For their experiments $0.023 \mathrm{~kg}$, 7.11-mm-diameter, 74.7-mm-long, spherical-nose, VAR 4340 steel projectiles as shown in Fig. 1 were launched into 250-mm-diameter, 6061-T6511 aluminum targets which were thick enough so the projectile would not perforate the target. Projectile striking velocities were measured using four laser-photodetector stations installed at various locations along the flight path. Pitch and yaw were photographed with an orthogonal pair of flash $\mathrm{x}$-rays positioned immediately in front of the face of the target. The final depth of penetration and shape of the projectile were obtained from post-test radiographs of 38-mm-thick slices of the targets.

\section{Analytical Model and Numerical Simulation}

In this section, we first present a closed form expression for the final depth of penetration that assumes the projectile is rigid and strikes the target at normal incidence. We then describe a new procedure developed by Warren and Tabbara (1997) for obtaining the final depth of penetration that is applicable for non-normal impacts by elastic-plastic projectiles. This new procedure utilizes the finite element method; however, it does 
eliminate the need for discretizing the target as well as the need for a contact algorithm. Both of the described methods use the SCE approximation (Forrestal et al., 1996) which approximates the target response with results from a dynamic, spherically symmetric cavity-expansion problem.

In addition, both of these penetration models neglect sliding frictional resistance at the projectile nose-target interface. We neglect sliding frictional resistance based on recent detailed computational models by Camacho and Ortiz (1997). Camacho and Ortiz (1997) performed finite-element simulations corresponding to experiments conducted by Forrestal et al. (1990) on the perforation of 5083-H131 aluminum plates with tungsten, conicalnosed projectiles These simulations use a new adaptive meshing technique and a constitutive material law that includes rate-dependent plasticity, heat conduction, and thermal coupling. Camacho and Ortiz (1997) conclude there is an exceedingly thin melted layer in the target next to the projectile that provides a nearly frictionless interface.

\section{Analytical Model}

In recent work (Forrestal et al., 1988; Forrestal et al., 1991; Forrestal et al., 1995; Forrestal and Tzou, 1996; and Warren and Forrestal, 1998) it has been shown that the radial stress at the cavity surface obtained from SCE models can be accurately represented by a function of the form

$$
\frac{\sigma_{r}(a)}{Y}=A+B\left(\sqrt{\frac{\rho_{o}}{Y}} \vartheta\right)+C\left(\sqrt{\frac{\rho_{o}}{Y}} \vartheta\right)^{2},
$$

where $\vartheta$ is the target particle velocity at the cavity-target interface, $a$ is the cavity radius, $Y$ is the quasi-static yield strength of the target material, $\rho_{o}$ is the density of the undeformed target material, and $A, B$, and $C$ are dimensionless fitting coefficients. Warren and Forrestal (1998) give the parameters in (1) for 6061-T6511 aluminum that account for compressibility, strain hardening, and strain-rate sensitivity. These values are summarized in Table 1.

Using (1) in Newton's second law and following the procedure outlined by Warren and Forrestal (1998) gives the final depth of penetration $P$ for a given striking velocity $V_{s}$ as 


$$
\begin{gathered}
\frac{P}{(L+2 a / 3)}=\frac{1}{C}\left(\frac{\rho_{p}}{\rho_{o}}\right)\left\{\ln \left[1+\frac{2 B}{3 A}\left(\sqrt{\frac{\rho_{o}}{Y}} V_{s}\right)+\frac{C}{2 A}\left(\sqrt{\frac{\rho_{o}}{Y}} V_{s}\right)^{2}\right]\right. \\
\left.+\frac{4 B}{\sqrt{18 A C-4 B^{2}}}\left[\tan ^{-1}\left[\frac{2 B}{\sqrt{18 A C-4 B^{2}}}\right]-\tan ^{-1}\left[\frac{3 C\left(\sqrt{\rho_{o} / Y} V_{s}\right)+2 B}{\sqrt{18 A C-4 B^{2}}}\right]\right]\right\},
\end{gathered}
$$

where $\rho_{p}$ is the density of the undeformed projectile material, $L$ is the shank length of the projectile, and it is assumed that the spherical-nosed projectile is rigid and strikes the target with normal incidence.

Finite Element Method

With the method described by Warren and Tabbara (1997) the same concept as used to obtain (2) is applied, but now in the context of a three dimensional finite element code. The spherical cavity-expansion forcing function given by (1) is implemented in PRONTO $3 \mathrm{D}$ as a normal traction (or pressure) boundary condition that acts on a prescribed surface. This new option has been added to the PRONTO 3D command language and is invoked as described by: Warren and Tabbara (1997). Four nodal pressures are calculated in PRONTO 3D for each element side (i.e. a side of a hexagonal continuum element or mid-surface of a structural shell element) that is included in a prescribed side set as shown in Fig. 2. These nodal pressures are obtained from

$$
p_{I_{*}}=c_{1}+c_{2}\left(\vec{V}_{I} \bullet \vec{n}\right)+c_{3}\left(\vec{V}_{I} \bullet \vec{n}\right)^{2} \quad(I=1,4)
$$

where the dot represents a scalar product, $\vec{V}_{l}$ is the nodal velocity vector, $\vec{n}$ is the outward unit vector normal to the diagonals of the element side, and the constant nodal pressure coefficients are related to the dimensionless fitting coefficients in (1) as $c_{1}=A Y$, $c_{2}=B\left(\rho_{o} Y\right)^{1 / 2}$, and $c_{3}=C \rho_{o}$. The values of $p_{I}$ are updated during each time increment using the current values of $\vec{V}_{I}$ and $\vec{n}$. If the scalar product $\left(\vec{V}_{I} \bullet \vec{n}\right)$ at a node is zero, negative, or if the node lies outside the bounds of where the cavity-expansion forcing function is defined then the pressure is set to zero for that node. A set of consistent global forces arising from these pressures over an element side are calculated as discussed by 
Taylor and Flanagan (1989). These forces are accumulated into an applied load vector as each element side in the side set is considered. The applied load vector is then incorporated into the equations of motion for the body which are integrated using a modified central difference integration scheme as discussed by Taylor and Flanagan (1989).

The finite element mesh used to model the spherical-nosed projectiles in all of the simulations is illustrated in Fig. 3. This mesh is constructed with 2784 eight-node constant strain hexahedral continuum elements, and has a total of 3172 nodes.

\section{Constitutive Model for VAR 4340 Steel}

The constitutive equations used for modeling the projectile in PRONTO 3D assume that the volumetric or dilatational response is governed by a pressure-volumetric strain relation while the shear or deviatoric response obeys a conventional flow theory of plasticity. Decomposing the Cauchy stress tensor into hydrostatic and deviatoric components gives

$$
\sigma_{i j}=-p \delta_{i j}+s_{i j}
$$

where $p$ is the hydrostatic pressure, $\delta_{i j}$ is the Kronecker delta, and $s_{i j}$ is the deviatoric stress tensor. The pressure-volumetric strain relation is

$$
p=-\frac{1}{3} \sigma_{i i}=-K \varepsilon_{i i}=K\left(1-\frac{\rho_{p}}{\rho}\right),
$$

where $K$ is the bulk modulus, $\varepsilon_{i i}$ is the volumetric strain, and $\rho$ is the density of the material in the deformed configuration.

Plastic flow is introduced through a Von-Mises elastic-viscoplastic material model similar to that used by Camacho and Ortiz (1997). The plastic strain rate is defined through the power law relationship

$$
\dot{\varepsilon}_{p}=\left\{\begin{array}{ll}
\dot{\varepsilon}_{p o}\left[\left(\frac{\bar{\sigma}}{g\left(\varepsilon_{p}\right)}\right)^{m}-1\right] & , \bar{\sigma} \geq g\left(\varepsilon_{p}\right) \\
0 & , \bar{\sigma}<g\left(\varepsilon_{p}\right)
\end{array},\right.
$$


where $\bar{\sigma}=\sqrt{3 / 2}\left(s_{i j} s_{i j}\right)^{1 / 2}$ is the Von-Mises effective stress, $g$ is the flow stress, $\varepsilon_{p}$ is the accumulated plastic strain, $\dot{\varepsilon}_{p o}$ is a reference plastic strain rate, and $m$ is the strain rate sensitivity exponent. We also employ a power hardening law in which

$$
g=Y_{p}\left(1+\frac{\varepsilon_{p}}{\varepsilon_{p o}}\right)^{1 / n}
$$

where $n$ is the strain hardening exponent, $\varepsilon_{p o}$ is a reference plastic strain, and $Y_{p}$ is the quasi-static yield stress of the material. The constitutive model in (6) uses a rate tangent method for time integration (Peirce et al., 1984) and was implemented in PRONTO 3D following the procedure described by Taylor and Flanagan (1989) for adding adding new constitutive models.

Additionally, default values of hourglass control and artificial bulk viscosity are applied to the numerical solution as discussed by Taylor and Flanagan (1989). Hourglass control is required because PRONTO 3D uses one point integration of an element which under-integrates the element resulting in a rank deficiency which manifests itself into spurious zero energy modes (hourglass modes) that must be constrained. Artificial bulk viscosity is employed to prevent high velocity gradients from collapsing an element before it has a chance to respond and also to quiet truncation frequency ringing.

We obtained constants for the constitutive equation (6) from compressive stressstrain data for VAR 4340 Rc 39 steel obtained by Mosher (1996) at a nominal strain rate (Ramesh and Narasimhan, 1996) of $0.098 \mathrm{~s}^{-1}$, Ravichandran (1997) at nominal strain rates of $0.001 s^{-1}, 0.1 s^{-1}, 1330 s^{-1}, 5380 s^{-1}$, and $8110 s^{-1}$, and also from pressure-shear data obtained by Ramesh (1997) at a nominal strain rate of $398371 \mathrm{~s}^{-1}$. The model parameters were obtained from curve fits to these data and are listed in Table 2. The undeformed density, Young's modulus, and Poisson's ratio of the VAR $4340 \mathrm{Rc} 39$ steel are taken to be $\rho_{p}=8025 \mathrm{~kg} / \mathrm{m}^{3}$ (the actual value is $7830 \mathrm{~kg} / \mathrm{m}^{3}$; however, we inceased the value slightly to account for mass lost in the discretization process), $E=206 \mathrm{Gpa}$, and $v=1 / 3$ respectively. Figure 4 compares the stress-strain data obtained by Mosher (1996) with the results from (6) and show good agreement. Figure 5 compares the stress data obtained by Mosher (1996), Ravichandran (1997), and Ramesh (1997) at a fixed strain of $14 \%$ with the results from (6) and good agreement is observed over the wide range of 
strain rates. We also require constants for VAR $4340 \mathrm{Rc} 37$ steel which we obtained by reducing the quasi-static yield strength. This required a change in $\varepsilon_{p o}$; however, all the other parameters remained the same as those obtained for the VAR $4340 \mathrm{Rc} 39$ steel as shown in Table 2. In Fig 6 stress data obtained by Ravichandran (1997) at a fixed strain of $14 \%$ for VAR 4340 Rc 37 steel is compared with the results from (6) and again good agreement is observed.

\section{Results and Discussion}

In this section, we present results from our simulations and compare these with the experimental results obtained by Forrestal and Piekutowski (1998) for VAR 4340 Rc 37 and Rc 39 spherical-nosed projectiles. Table 3 summarizes the initial conditions and final depths of penetration obtained from the experiments by Forrestal and Piekutowski (1998) in the response region before the projectiles exhibited excessive deformation. Because there was no angle of obliquity (i.e. velocity vector is normal to the target) pitch and yaw are resolved into a single angle of inclination.

First we consider the case of a VAR 4340 Rc 37 spherical-nosed projectile striking a 6061 -T6511 aluminum target with a striking velocity of $720 \mathrm{~m} / \mathrm{s}$ without any angle of inclination. Images of the simulation at four specific times are shown in Fig. 7. From these images it is observed that the projectile initially bulges symmetrically and then follows a straight path until it finally comes to rest at approximately $204 \mu \mathrm{s}$. This result is consistent with what is obtained when a penetration event is modeled as being axisymmetric (Chen, 1990; Chen, 1995; Camacho and Ortiz, 1997, etc.). In reality however, there is always going to be some amount of pitch and yaw associated with any ballistic event. With this in mind we now consider the same problem with one degree of inclination as was observed with the experiment by Forrestal and Piekutowski (1998). Images of the simulation at four specific times are shown in Fig. 8. From these images it is observed that the projectile initially bulges and bends to the right because of the unsymmetric loading due to the one degree angle of inclination. As the event continues the tail bends to the left producing a curvature in the projectile. Figure 9 compares the final position of the projectile with the post-test radiograph obtained from the experiment by Forrestal and Piekutowski (1998). This result indicates that using the SCE forcing function in the simulation allows for an accurate prediction of the permanent projectile deformation. Furthermore, it is clearly observed from this result that even a small amount of inclination (i.e. one degree) can have a significant effect on the projectiles performance. 
Selected final projectile positions obtained from the simulations are compared in Figs. 10 through 14 with the corresponding post-test radiographs obtained from the experiments by Forrestal and Piekutowski (1998). These results again indicate that the SCE forcing function used in the simulations allows for the accurate prediction of the permanent projectile deformation provided the projectile does not deform excessively. The SCE approximation used here will not adequatly model the target resistance if the projectile deforms in a manner such that it leaves a void space behind in which material from the projectile can flow into the void space without resistance. The reason for this is because the SCE approximation checks for a positive velocity component normal to the surface of the projectile and if there is it applies a load.

Values of the final depth of penetration obtained from the simulations are included in Table 3 for comparison with the experimental values. These results are also plotted in Fig. 15 and compared with the results obtained from the rigid projectile model given in (2). It is shown that the rigid projectile model always over predicts the final depth of penetration. The reason for this is energy is lost due to projectile deformation in the bulging and bending processes, and this is not accounted for with the rigid projectile model.

\section{Summary}

We have conducted simulations of the penetration of 6061-T6511 aluminum targets by VAR $4340 \mathrm{Rc} 37$ and Rc39 spherical nosed projectiles in order to validate the use of experimentally verified analytical functions to represent the target resistance in ballistic events. Comparison with experimental results indicates that over a wide range of striking velocities this method allows for the accurate prediction of permanent projectile deformation provided the projectile doesn't deform excessively. Thus, for the class of problems within the realm of assumptions considered here, this technique is efficient and robust and can be included in a broader software tool which can be utilized for design purposes.

\section{Acknowledgments}

This work was supported by the United States Department of Energy and the Joint DoD/DOE Munitions Technology Development Program. Sandia is a multiprogram laboratory operated by Sandia Corporation, a Lockheed Martin Company, for the United States Department of Energy under Contract DE-AC04-94AL85000. The authors also 
gratefully acknowledge numerous discussions with M.J. Forrestal, D.A. Mosher, K.T. Ramesh, and G. Ravichandran. 


\section{References}

Adley, M.D., and R.E. Moxley, (1996), PENCURV/ABAQUS: a simply coupled penetration trajectory/structural dynamics model for deformable projectiles impacting complex curvilinear targets, Technical Report SL-96-6, U.S. Army Engineer Waterways Experiment Station, Vicksburg, MS 39180.

Bishop, R.F., Hill, R., and Mott, N.F., (1945), "The theory of indentation and hardness," Proc. Roy. Soc., Vol. 57 (3), pp. 147-159.

Camacho, G.T., and Ortiz, M. , (1997), “Adaptive Lagrangian modeling of ballistic penetration of metallic targets," Comput. Meth. Appl. Mech. Eng., Vol. 142, pp 269-301.

Chen, E.P., (1990), Finite element simulation of perforation and penetration of aluminum targets by conical-nosed steel rods, Mech. Mater., Vol. 10, pp. 107-115.

Chen, E.P., (1995), "Numerical simulation of penetration of aluminum targets by spherical-nose steel rods," Theoretical and Applied Fracture Mechanics, Vol. 22, pp. 159-164.

Duffey, T.A., and R.W. Macek, (1997), Non-normal impact of earth penetrators, Proceedings of the International Symposium on Penetration and Impact Problems (ICES'97), San Jose, Costa Rica.

Forrestal, M.J., K. Okajima, and V.K. Luk, (1988), Penetration of 6061-T651 aluminum targets with rigid long rods, ASME Journal of Applied Mechanics, Vol. 55, pp. $755-760$.

Forrestal, M.J., Luk, V.K., and Brar, N.S., (1990), Penetration of aluminum armor plates with conical-nose projectiles, Mech. Mater, Vol. 10, pp. 97-105.

Forrestal, M.J., N.S. Brar, and V.K. Luk, (1991), Penetration of strain-hardening targets with rigid spherical-nose rods, ASME Journal of Applied Mechanics, Vol. 58, pp. $7-10$. 
Forrestal, M.J., and D.Y. Tzou, E. Askari, and D.B. Longcope, (1995), Penetration into ductile metal targets with rigid spherical-nose rods, Int. J. Impact Engng., Vol. 16, pp.699-710.

Forrestal, M.J., D.Y. Tzou, (1996), A spherical cavity-expansion penetration model for concrete targets, Int. J. Solids Structures, Vol. 34 (31-32), pp. 4127-4146.

Forrestal, M.J., A.J. Piekutowski, (1998), Penetration of aluminum targets with sphericalnose steel projectiles at striking velocities between 0.5 and $3.0 \mathrm{~km} / \mathrm{s}$, in preperation.

Goodier, J.N. (1965), On the mechanics of indentation and cratering in the solid targets of strain-hardening metal by impact of hard and soft spheres, Proceedings of the 7 th Symposium on Hypervelocity Impact III, pp. 215-259.

Hibbitt, Karlsson, and Sorensen, Inc., (1989), ABAQUS Users Manual, Version 4-8, Providence, RI.

Hill, R., (1948), A theory of earth movement near a deep underground explosion, Memo No. 21-48, Armament Research Establishment, Fort Halstead, Kent, UK.

Hill, R., (1950), The Mathematical Theory of Plasticity, Oxford University Press, London.

Hopkins, H.G., (1960), Dynamic expansion of spherical cavities in metals, Progress in Solid Mechanics Vol. 1, eds. I. Sneddon, and R. Hill, North Holland, New York, pp.85-164.

Johnson, G.R., R.A. Stryk, T.J. Holmquist, and S.R. Beissel, (1997), EPIC 97, software to be released, Alliant Techsystems Inc., Hopkins, MN.

Longcope, D.B., (1991), Coupled bending/lateral load modeling of earth penetrators, SAND90-0789, Sandia National Laboratories, Albuquerque, NM..

Longcope, D.B., (1996), Oblique penetration modeling and correlation with field tests into a soil target, SAND96-2239, Sandia National Laboratories, Albuquerque, NM. 
Mosher, D. A., (1996), Results from 6061-T6511 aluminum and 4340 steel testing, private communication, Sandia National Laboratories, Livermore, CA 94551-0969, USA.

Peirce, D, C.F. Shih, and A. Needleman, (1984), A tangent modulus method for rate dependent solids, Comp. Struct., Vol. 18 (5), pp. 875-887.

Ramesh, K.T., and Narasimhan, S., (1996), Finite deformations and the dynamic measurement of radial strains in compression Kolsky bar expariments," Int. $J$. Solids Structures, Vol. 33, pp. 3723-3738.

Ramesh, K.T., (1997), High strain rate behavior in 4340 steel, private communication, The Johns Hopkins University, Baltimore, MD 21218, USA.

Ravichandran, G., (1997), Mechanical testing of 6061-T651 aluminum alloy and 4340 steel, private communication, California Institute of Technology, Pasadena, CA 91125, USA.

Taylor, L.M. and D.P. Flanagan, (1989), PRONTO 3D a three-dimensional transient solid dynamics program, SAND87-1912, Sandia National Laboratories, Albuquerque, NM.

Warren, T.L. and M.R. Tabbara, (1997), Spherical Cavity-Expansion Forcing Function in PRONTO 3D for Application to Penetration Problems, SAND97-1174, Sandia National Laboratories, Albuquerque, NM.

Warren, T.L. and M.J. Forrestal, (1998), Effects of strain hardening and strain-rate sensitivity on the penetration of aluminum targets with spherical-nosed rods, Int. $J$. Solids Structures, Vol. 35, Nos 28-29, pp. 3737-3753. 


\section{List of Figures}

Figure 1. Projectile geometry.

Figure 2. Definition of a pressure boundary condition that acts on an element side.

Figure 3. Finite element mesh of a spherical-nose projectile.

Figure 4. Stress-strain data and data fit for VAR $4340 \mathrm{Rc} 39$ steel at a nominal strain rate of $\dot{\varepsilon}=0.098 s^{-1}$

Figure 5. Rate sensitivity diagram for VAR $4340 \mathrm{Rc} 39$ steel at a fixed strain of $14 \%$.

Figure 6. Rate sensitivity diagram for VAR $4340 \mathrm{Rc} 37$ steel at a fixed strain of $14 \%$.

Figure 7. Simulation of a VAR $4340 \mathrm{Rc} 37$ spherical-nose projectile penetrating 6061T6511 aluminum with $V_{s}=720 \mathrm{~m} / \mathrm{s}$ and $0^{\circ}$ angle of inclination: (a) $\mathrm{t}=0 \mathrm{~s}$, (b) $\mathrm{t}=30 \mu \mathrm{s}$, (c) $\mathrm{t}=102 \mu \mathrm{s}$, and (d) $\mathrm{t}=204 \mu \mathrm{s}$.

Figure 8. Simulation of a VAR $4340 \mathrm{Rc} 37$ spherical-nose projectile penetrating 6061T6511 aluminum with $V_{s}=720 \mathrm{~m} / \mathrm{s}$ and $1^{\circ}$ angle of inclination: (a) $t=0 \mathrm{~s}$, (b) $\mathrm{t}=30 \mu \mathrm{s}$, (c) $\mathrm{t}=102 \mu \mathrm{s}$, and (d) $\mathrm{t}=204 \mu \mathrm{s}$.

Figure 9. Final projectile position of a VAR $4340 \mathrm{Rc} 37$ spherical-nose projectile penetrating 6061-T6511 aluminum with $\mathrm{V}_{s}=720 \mathrm{~m} / \mathrm{s}$ and $1^{\circ}$ angle of inclination: (a) simulation, and (b) post-test radiograph.

Figure 10. Final projectile position of a VAR $4340 \mathrm{Rc} 37$ spherical-nose projectile penetrating 6061-T6511 aluminum with $\mathrm{V}_{\mathrm{s}}=892 \mathrm{~m} / \mathrm{s}$ and $0.9^{\circ}$ angle of inclination: (a) simulation, and (b) post-test radiograph.

Figure 11. Final projectile position of a VAR $4340 \mathrm{Rc} 39$ spherical-nose projectile penetrating 6061-T6511 aluminum with $V_{s}=572 \mathrm{~m} / \mathrm{s}$ and $1.3^{\circ}$ angle of inclination: (a) simulation, and (b) post-test radiograph.

Figure 12. Final projectile position of a VAR $4340 \mathrm{Rc} 39$ spherical-nose projectile penetrating 6061-T6511 aluminum with $\mathrm{V}_{\mathrm{s}}=781 \mathrm{~m} / \mathrm{s}$ and $2.9^{\circ}$ angle of inclination: (a) simulation, and (b) post-test radiograph.

Figure 13. Final projectile position of a VAR $4340 \mathrm{Rc} 39$ spherical-nose projectile penetrating 6061-T6511 aluminum with $\mathrm{V}_{\mathrm{s}}=821 \mathrm{~m} / \mathrm{s}$ and $1.7^{\circ}$ angle of inclination: (a) simulation, and (b) post-test radiograph.

Figure 14. Final projectile position of a VAR $4340 \mathrm{Rc} 39$ spherical-nose projectile penetrating 6061-T6511 aluminum with $V_{s}=932 \mathrm{~m} / \mathrm{s}$ and $0.7^{\circ}$ angle of inclination: (a) simulation, and (b) post-test radiograph.

Figure 15. Depth of penetration vs striking velocity obtained from simulations and penetration data. 
Table 1

6061-T6511 Aluminum Data

\begin{tabular}{|c|c|c|c|c|}
\hline $\begin{array}{c}\mathrm{Y} \\
(\mathrm{MPa})\end{array}$ & $\begin{array}{c}\rho_{\mathrm{o}} \\
\left(\mathrm{kg} / \mathrm{m}^{3}\right)\end{array}$ & $\mathrm{A}$ & $\mathrm{B}$ & $\mathrm{C}$ \\
\hline 276 & 2710 & 5.0394 & 0.9830 & 0.9402 \\
\hline
\end{tabular}


Table 2

VAR 4340 Steel Data

\begin{tabular}{|c|c|c|c|c|c|}
\hline VAR 4340 & $\begin{array}{c}Y_{p} \\
(\mathrm{MPa})\end{array}$ & $\varepsilon_{p o}$ & $\begin{array}{c}\dot{\varepsilon}_{p o} \\
(1 / \mathrm{s})\end{array}$ & $n$ & $m$ \\
\hline $\operatorname{Rc} 37$ & 1116 & $5.417 \times 10^{-3}$ & $5.940 \times 10^{-4}$ & 25.0 & 83.3 \\
\hline $\operatorname{Rc} 39$ & 1225 & $5.947 \times 10^{-3}$ & $5.940 \times 10^{-4}$ & 25.0 & 83.3 \\
\hline
\end{tabular}


Table 3

Penetration Results

\begin{tabular}{|c|c|c|c|}
\hline $\begin{array}{c}\mathrm{V}_{\mathrm{s}} \\
(\mathrm{m} / \mathrm{s})\end{array}$ & $\begin{array}{c}\text { Inclination } \\
\text { (Degrees) }\end{array}$ & $\begin{array}{c}\text { Experimental } \\
P \\
(\mathrm{~mm})\end{array}$ & $\begin{array}{c}\text { SCE/PRONTO 3D } \\
P \\
(\mathrm{~mm})\end{array}$ \\
\hline \multicolumn{3}{|c|}{ Nominal Rc 37 Projectiles } \\
\hline 720 & 1.0 & 67.8 & 65.5 \\
\hline 806 & 1.8 & 74.7 & 74.4 \\
\hline 892 & 0.9 & 84.1 & 87.0 \\
\hline \multicolumn{4}{|c|}{ Nominal Rc 39 Projectiles } \\
\hline 496 & 0.3 & 37.6 & 40.8 \\
\hline 572 & 1.3 & 48.1 & 49.6 \\
\hline 781 & 2.9 & 72.7 & 71.3 \\
\hline 821 & 1.7 & 84.3 & 79.8 \\
\hline 841 & 0 & 91.4 & 83.5 \\
\hline 932 & 0.7 & 96.5 & 100.5 \\
\hline 967 & 0.3 & 94.4 & \\
\hline
\end{tabular}




\section{List of Figures}

Figure 1. Projectile geometry.

Figure 2. Definition of a pressure boundary condition that acts on an element side.

Figure 3. Finite element mesh of a spherical-nose projectile.

Figure 4. Stress-strain and data fit for VAR $4340 \mathrm{Rc} 39$ steel at a nominal strain rate of $\dot{\varepsilon}=0.098 s^{-1}$

Figure 5. Rate sensitivity diagram for VAR $4340 \mathrm{Rc} 39$ steel at a fixed strain of $14 \%$.

Figure 6. Rate sensitivity diagram for VAR $4340 \mathrm{Rc} 37$ steel at a fixed strain of $14 \%$.

Figure 7. Simulation of a VAR $4340 \mathrm{Rc} 37$ spherical-nose projectile penetrating 6061 T6511 aluminum with $V_{s}=720 \mathrm{~m} / \mathrm{s}$ and $0^{\circ}$ angle of inclination: (a) $t=0 \mathrm{~s}$, (b) $t=30 \mu \mathrm{s}$, (c) $t=102 \mu \mathrm{s}$, and (d) $\mathrm{t}=204 \mu \mathrm{s}$.

Figure 8. Simulation of a VAR $4340 \mathrm{Rc} 37$ spherical-nose projectile penetrating 6061T6511 aluminum with $V_{s}=720 \mathrm{~m} / \mathrm{s}$ and $1^{\circ}$ angle of inclination: (a) $t=0 \mathrm{~s}$, (b) $t=30 \mu \mathrm{s}$, (c) $t=102 \mu \mathrm{s}$, and (d) $\mathrm{t}=204 \mu \mathrm{s}$.

Figure 9. Final projectile position of a VAR $4340 \mathrm{Rc} 37$ spherical-nose projectile penetrating 6061-T6511 aluminum with $\mathrm{V}_{\mathrm{s}}=720 \mathrm{~m} / \mathrm{s}$ and $1^{\circ}$ angle of inclination: (a) simulation, and (b) post-test radiograph.

Figure 10. Final projectile position of a VAR $4340 \mathrm{Rc} 37$ spherical-nose projectile penetrating 6061-T6511 aluminum with $\mathrm{V}_{\mathrm{s}}=892 \mathrm{~m} / \mathrm{s}$ and $0.9^{\circ}$ angle of inclination: (a) simulation, and (b) post-test radiograph.

Figure 11. Final projectile position of a VAR $4340 \mathrm{Rc} 39$ spherical-nose projectile penetrating 6061-T6511 aluminum with $\mathrm{V}_{\mathrm{s}}=572 \mathrm{~m} / \mathrm{s}$ and $1.3^{\circ}$ angle of inclination: (a) simulation, and (b) post-test radiograph.

Figure 12. Final projectile position of a VAR $4340 \mathrm{Rc} 39$ spherical-nose projectile penetrating 6061-T6511 aluminum with $\mathrm{V}_{\mathrm{s}}=781 \mathrm{~m} / \mathrm{s}$ and $2.9^{\circ}$ angle of inclination: (a) simulation, and (b) post-test radiograph.

Figure 13. Final projectile position of a VAR $4340 \mathrm{Rc} 39$ spherical-nose projectile penetrating 6061-T6511 aluminum with $\mathrm{V}_{\mathrm{s}}=821 \mathrm{~m} / \mathrm{s}$ and $1.7^{\circ}$ angle of inclination: (a) simulation, and (b) post-test radiograph.

Figure 14. Final projectile position of a VAR $4340 \mathrm{Rc} 39$ spherical-nose projectile penetrating 6061-T6511 aluminum with $V_{s}=932 \mathrm{~m} / \mathrm{s}$ and $0.7^{\circ}$ angle of inclination: (a) simulation, and (b) post-test radiograph.

Figure 15. Depth of penetration vs striking velocity obtained from simulations and penetration data. 


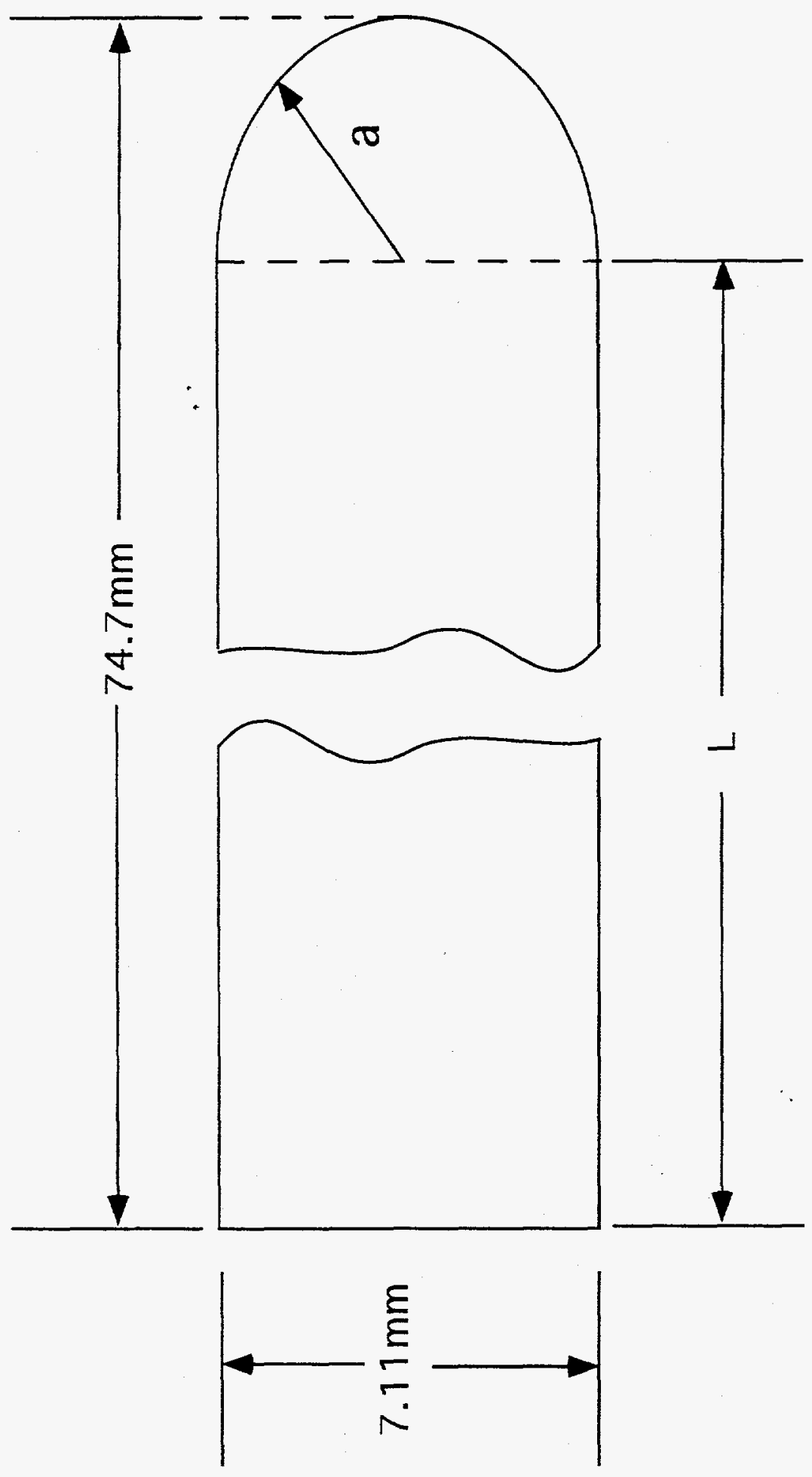

Fig. 1 

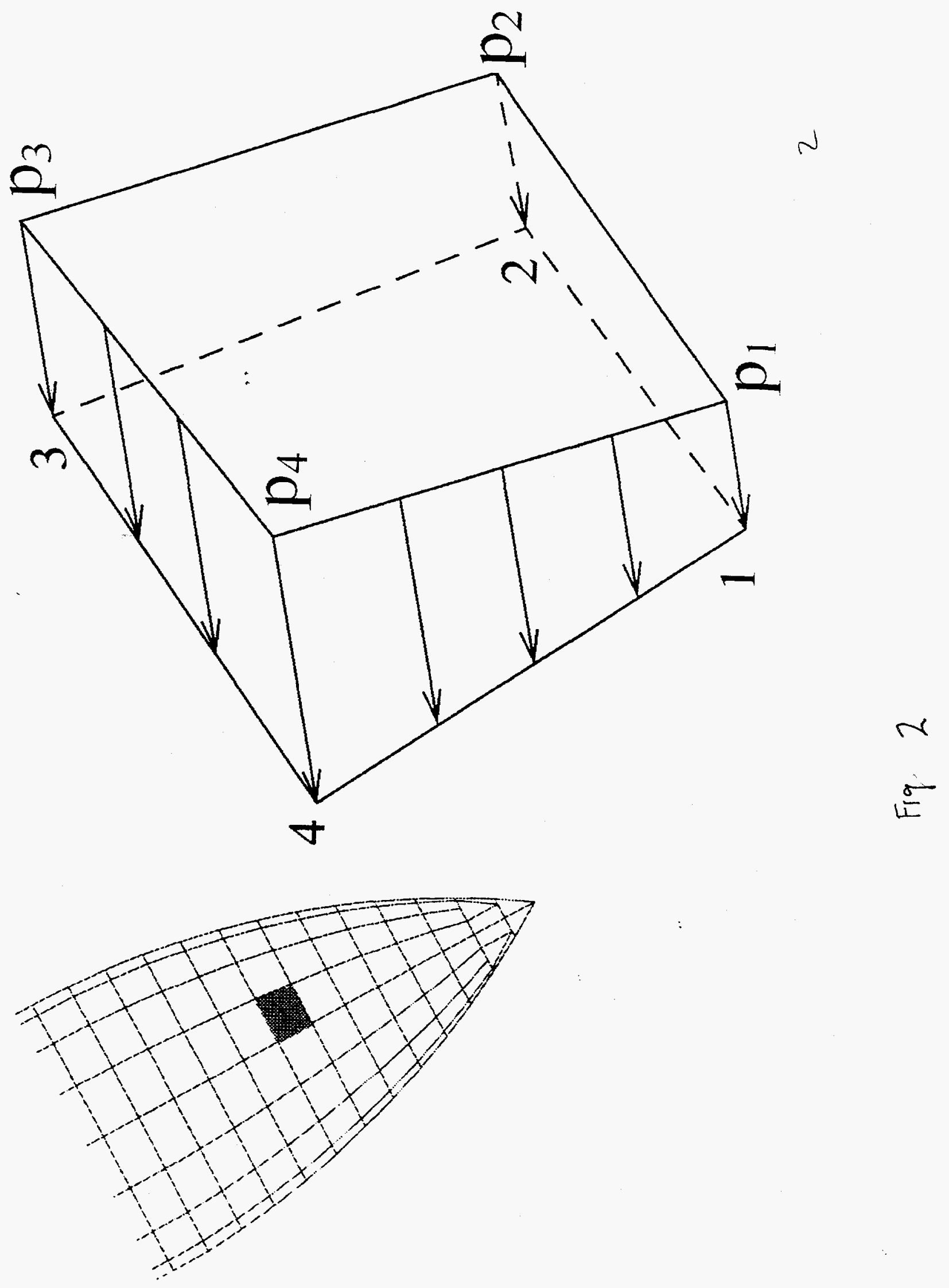


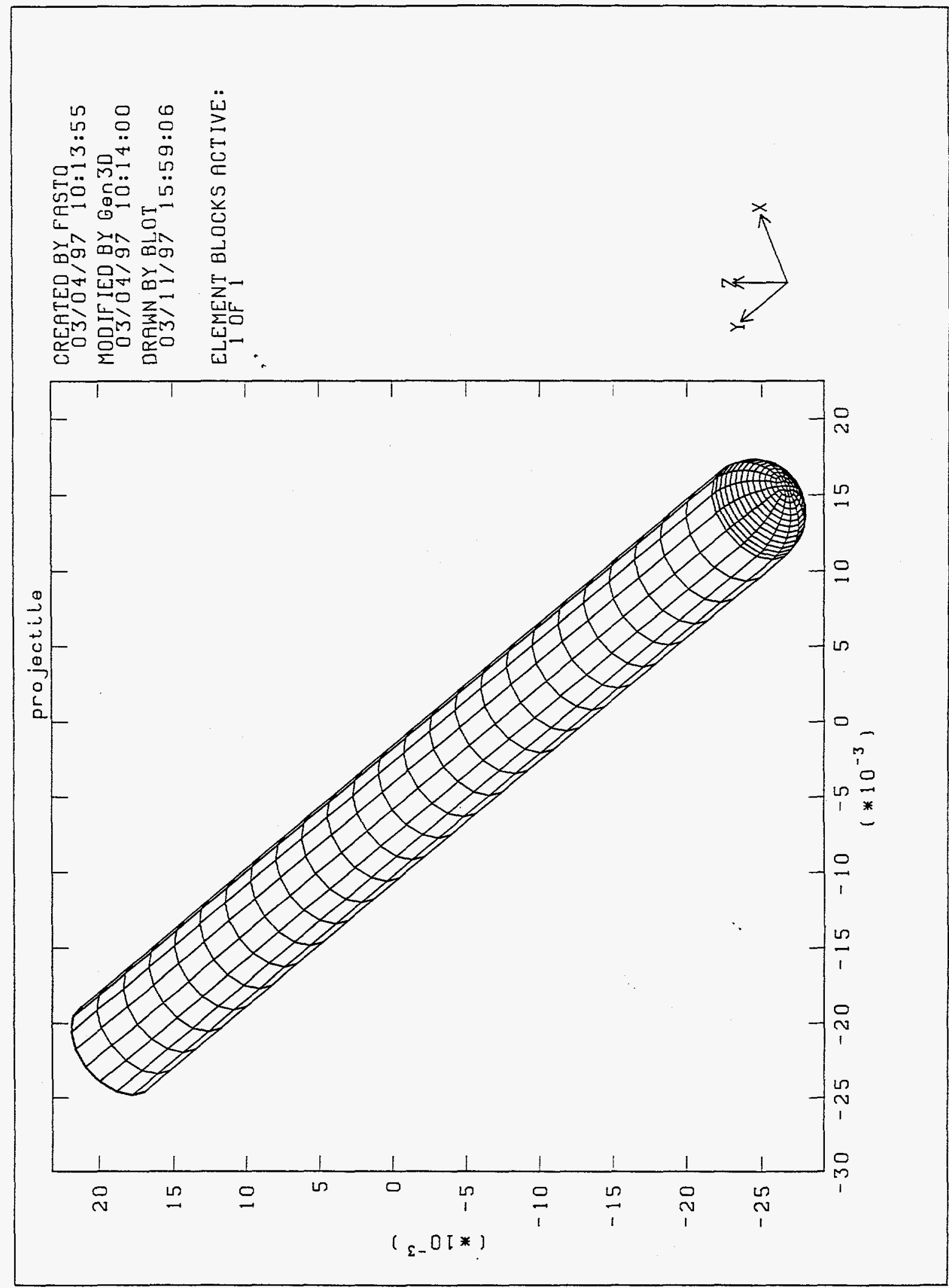




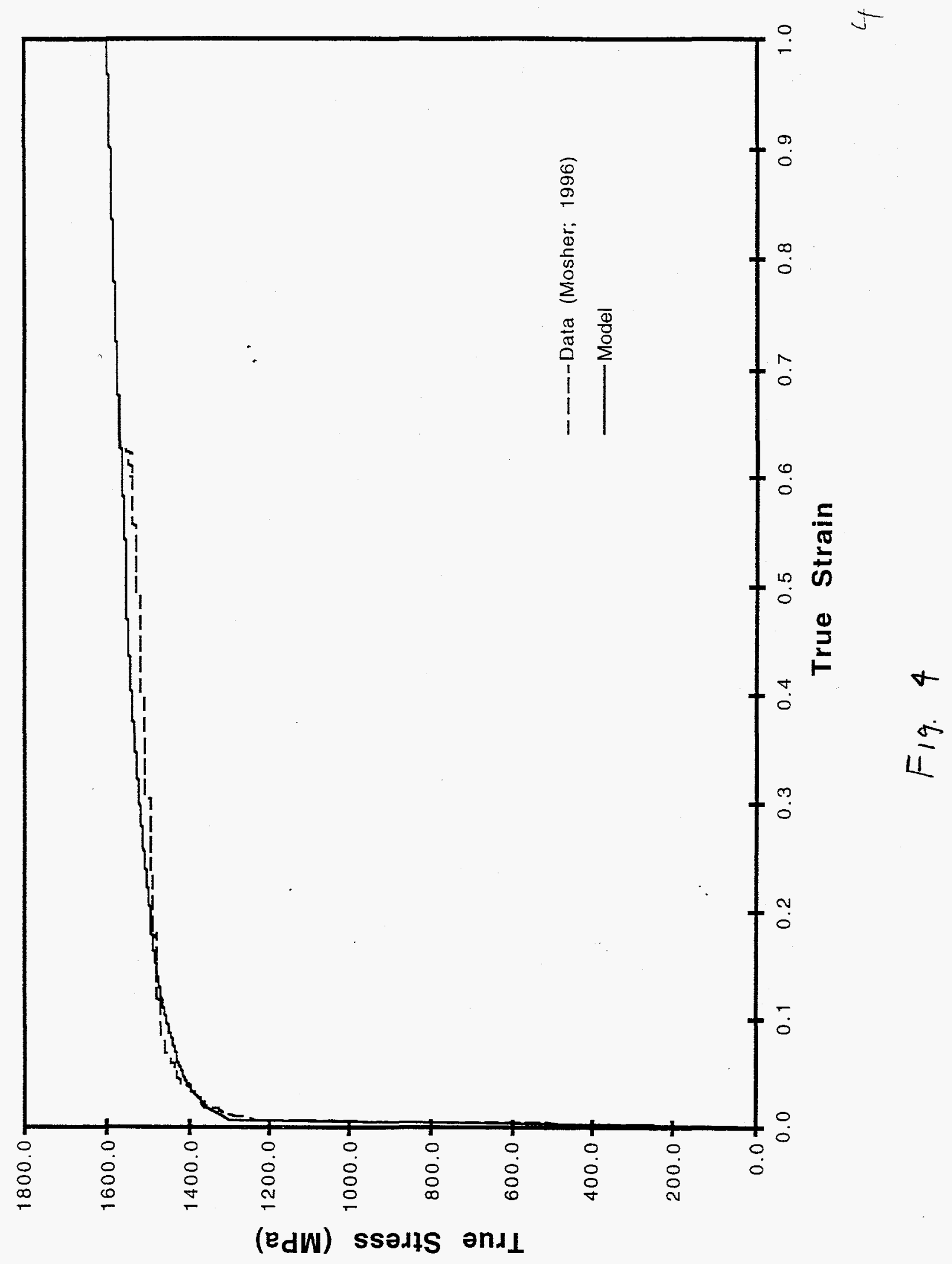




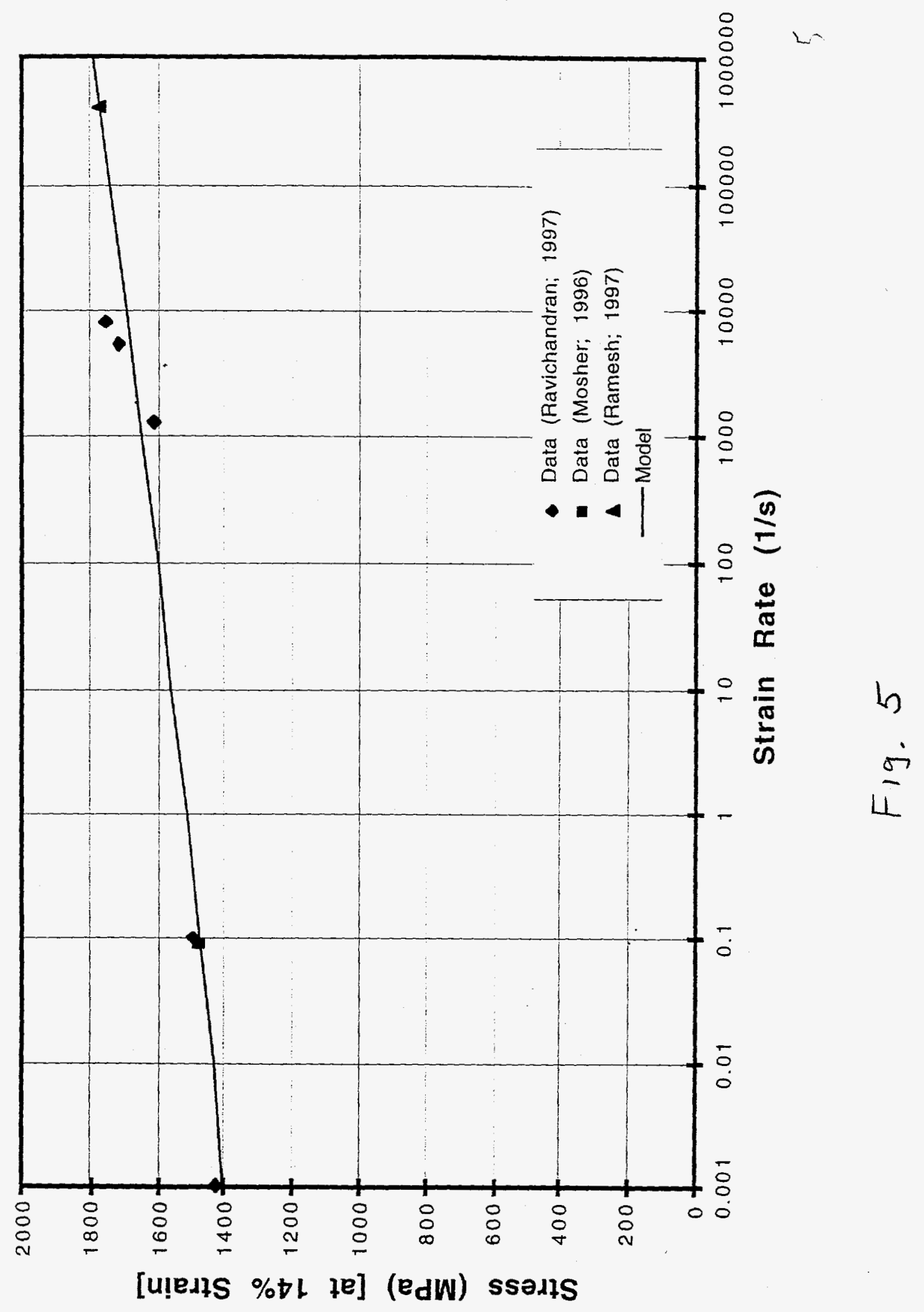




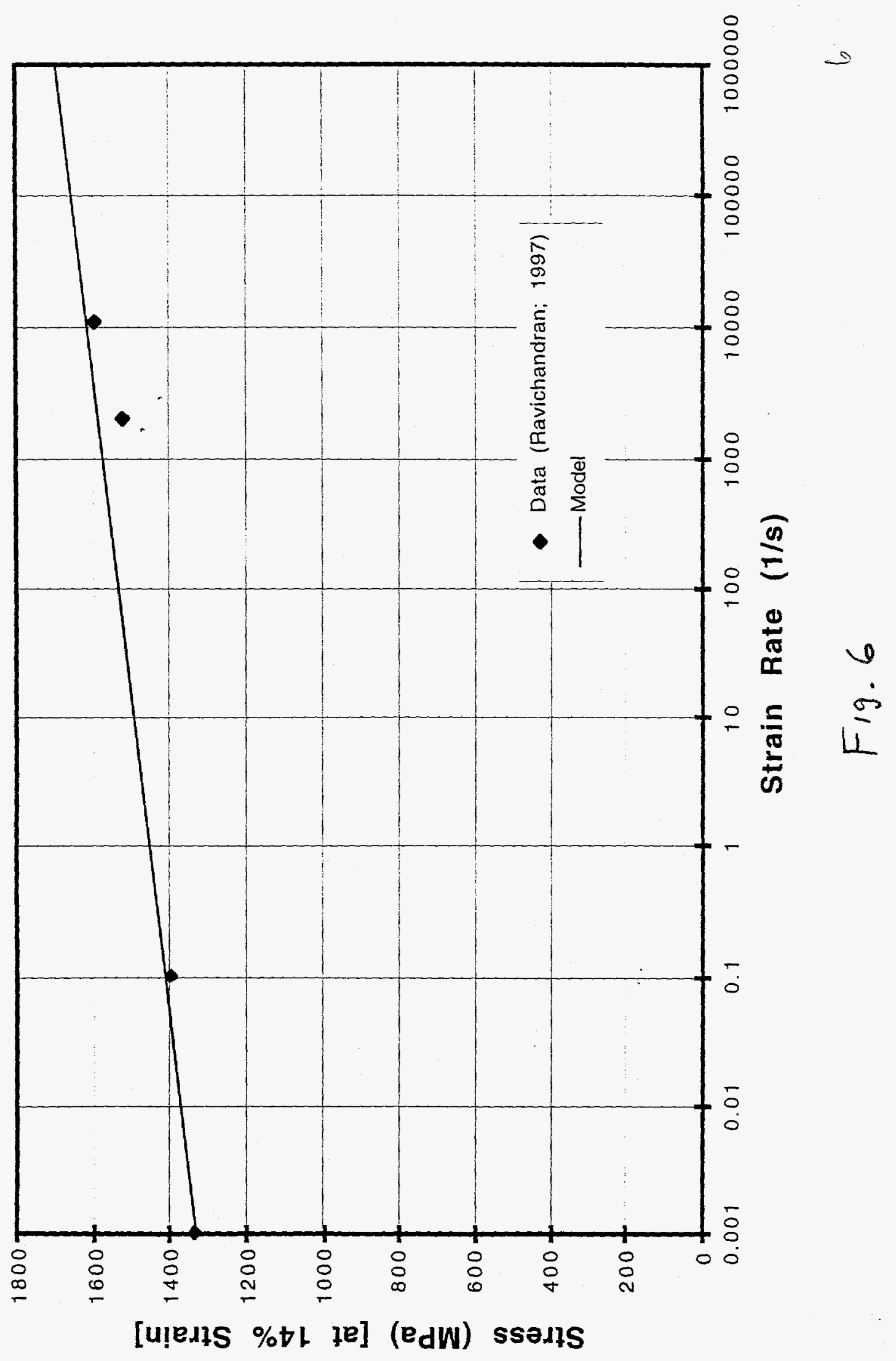



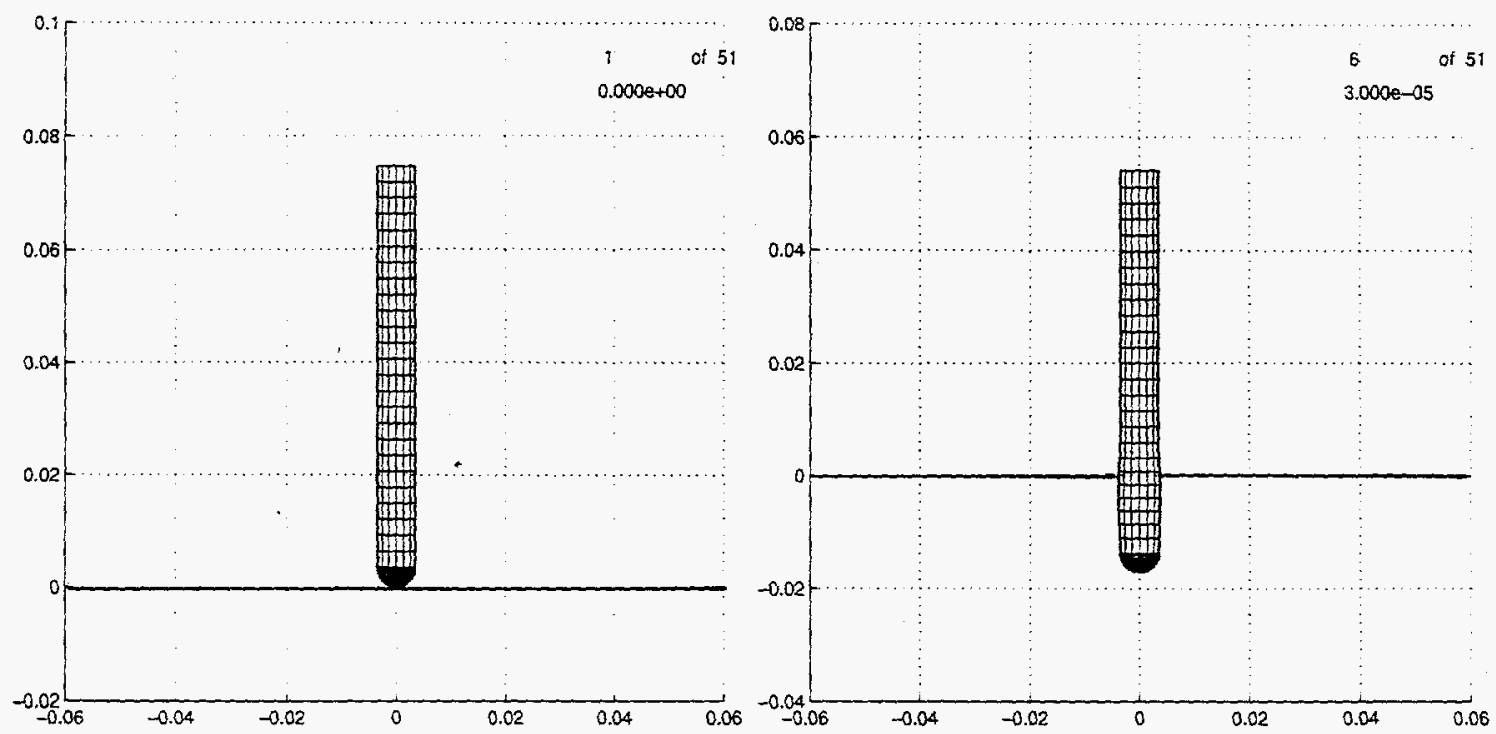

(a)

(b)
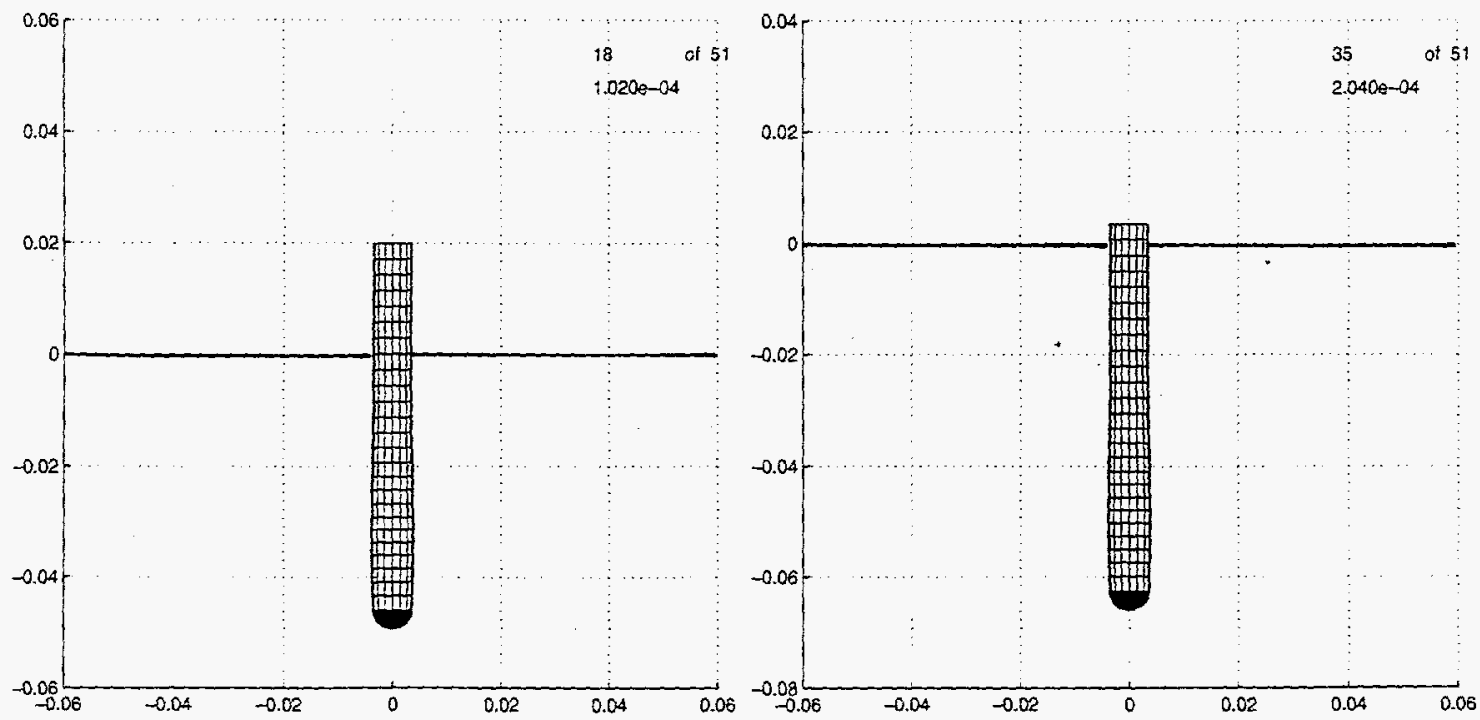

(c)

(d)

Fig. 9 

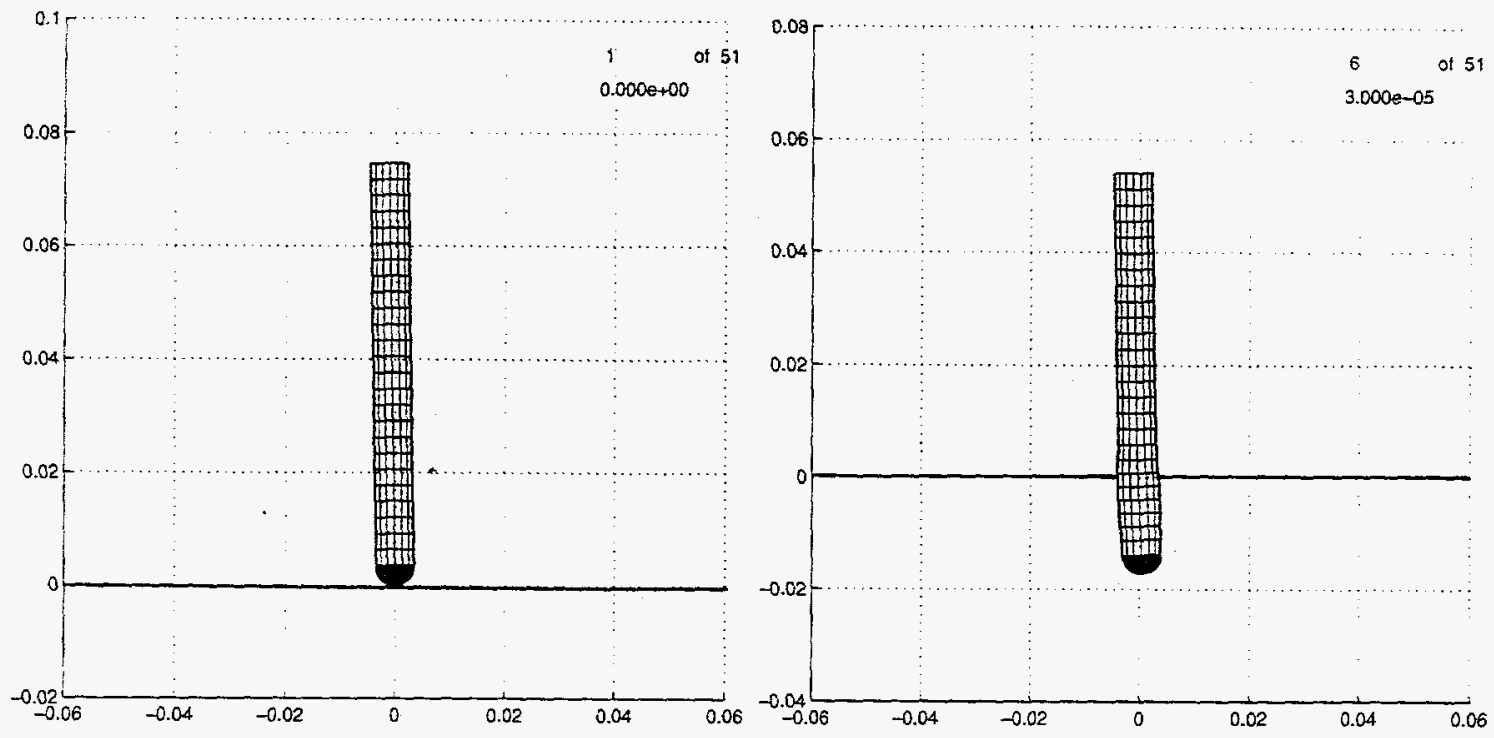

(a)

(b)

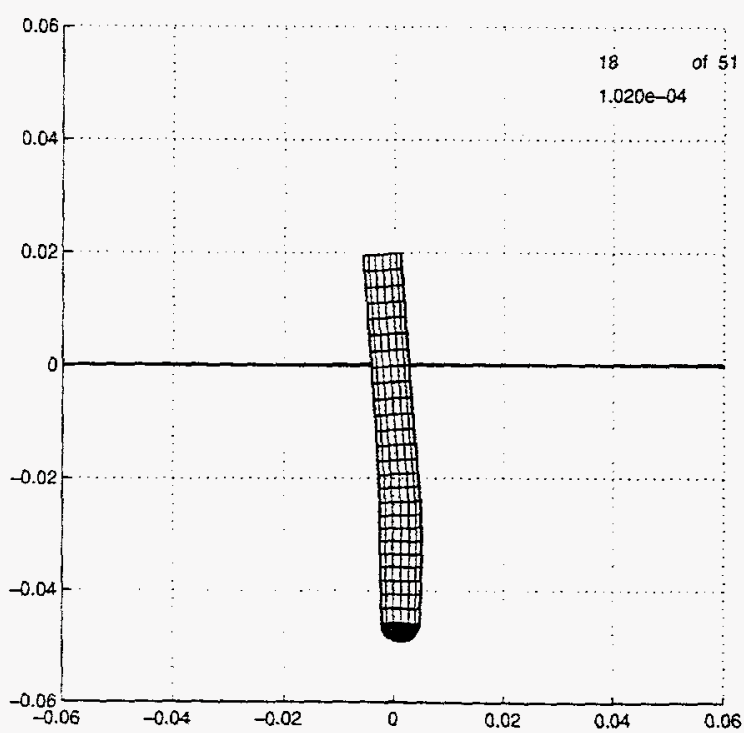

(c)

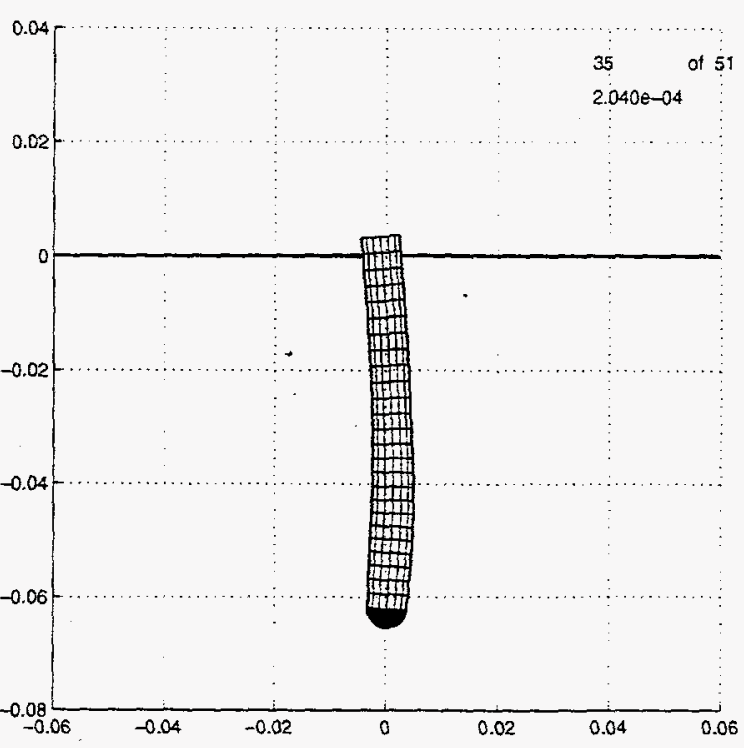

(d) 


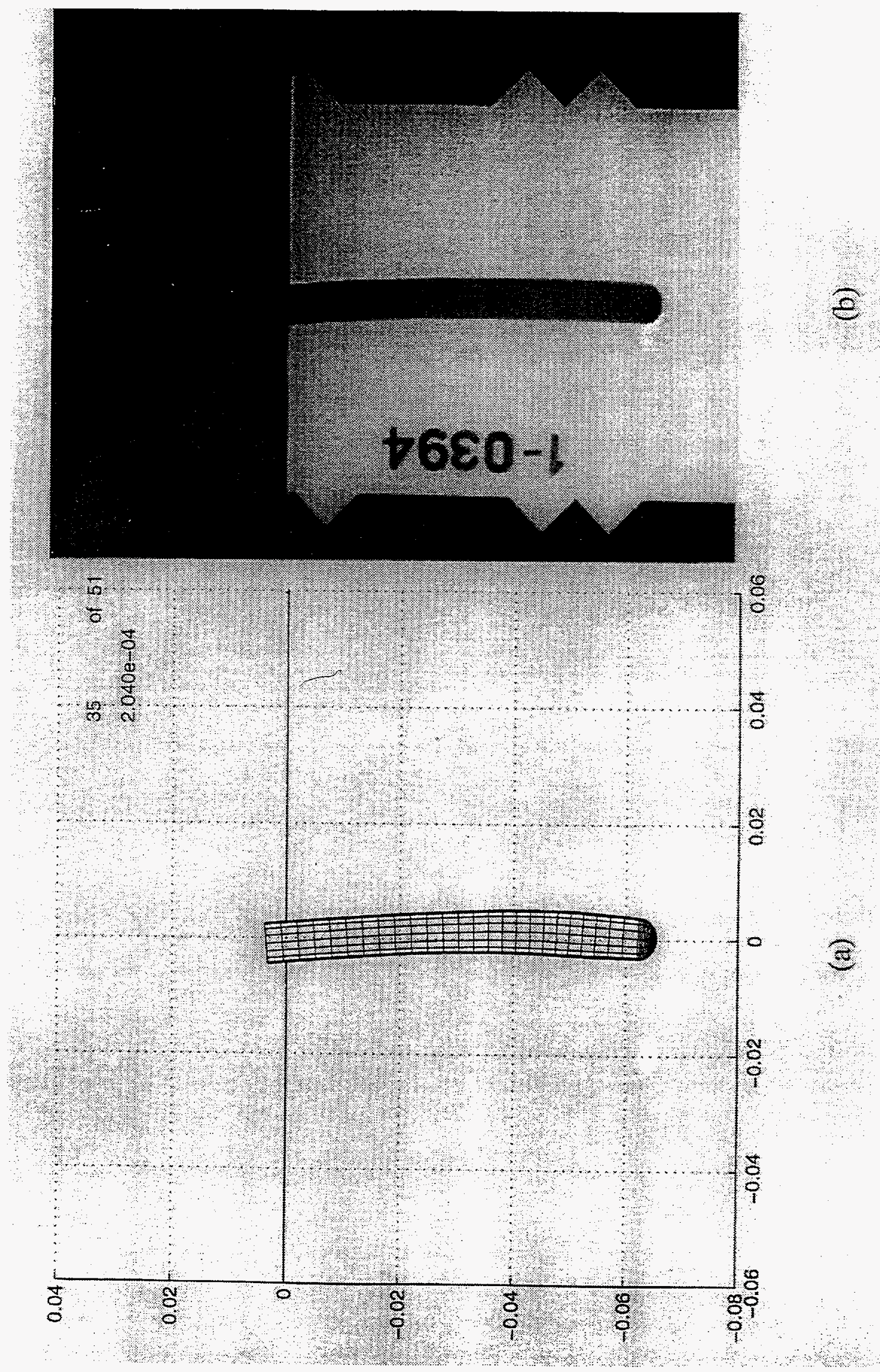




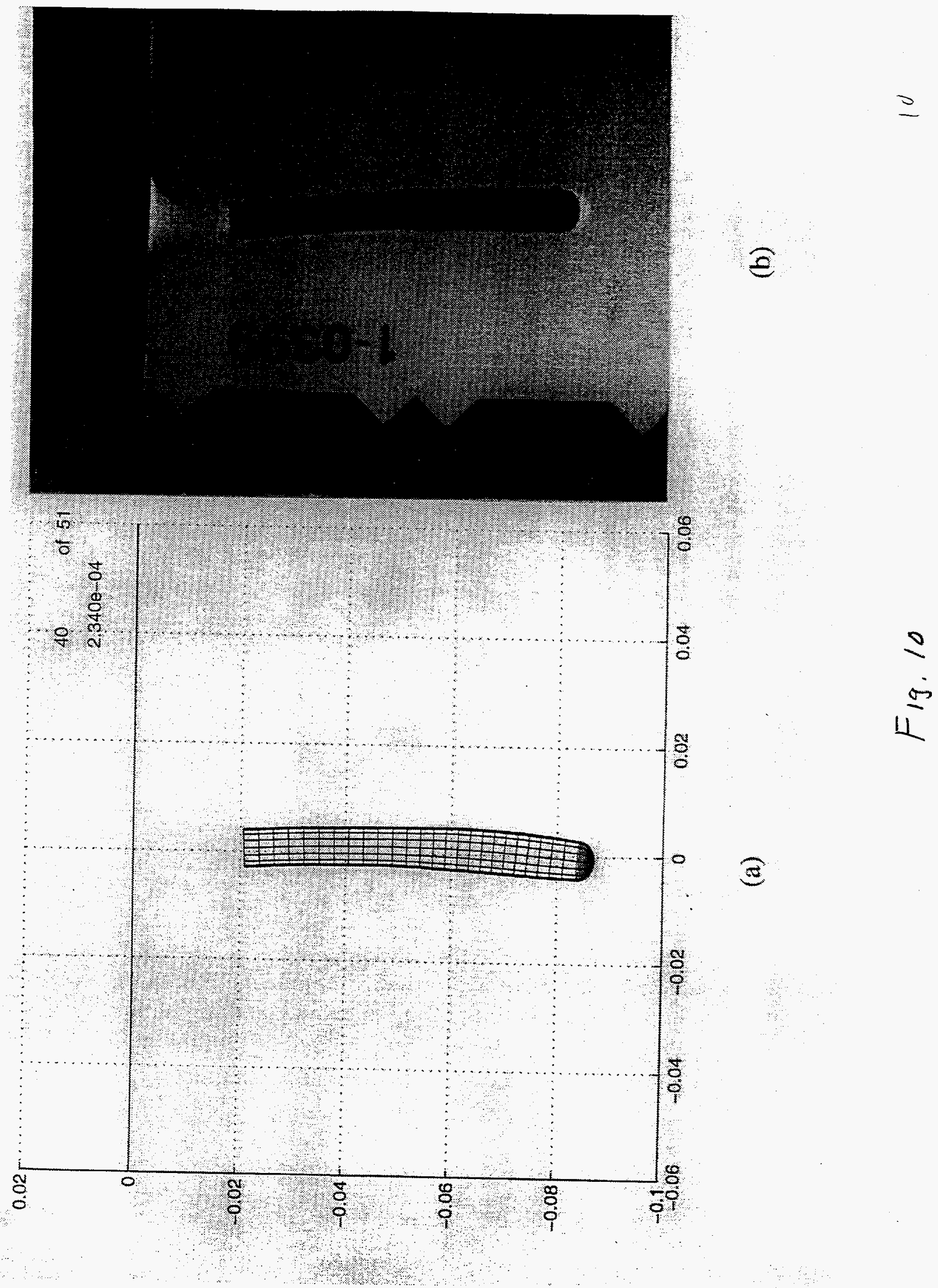




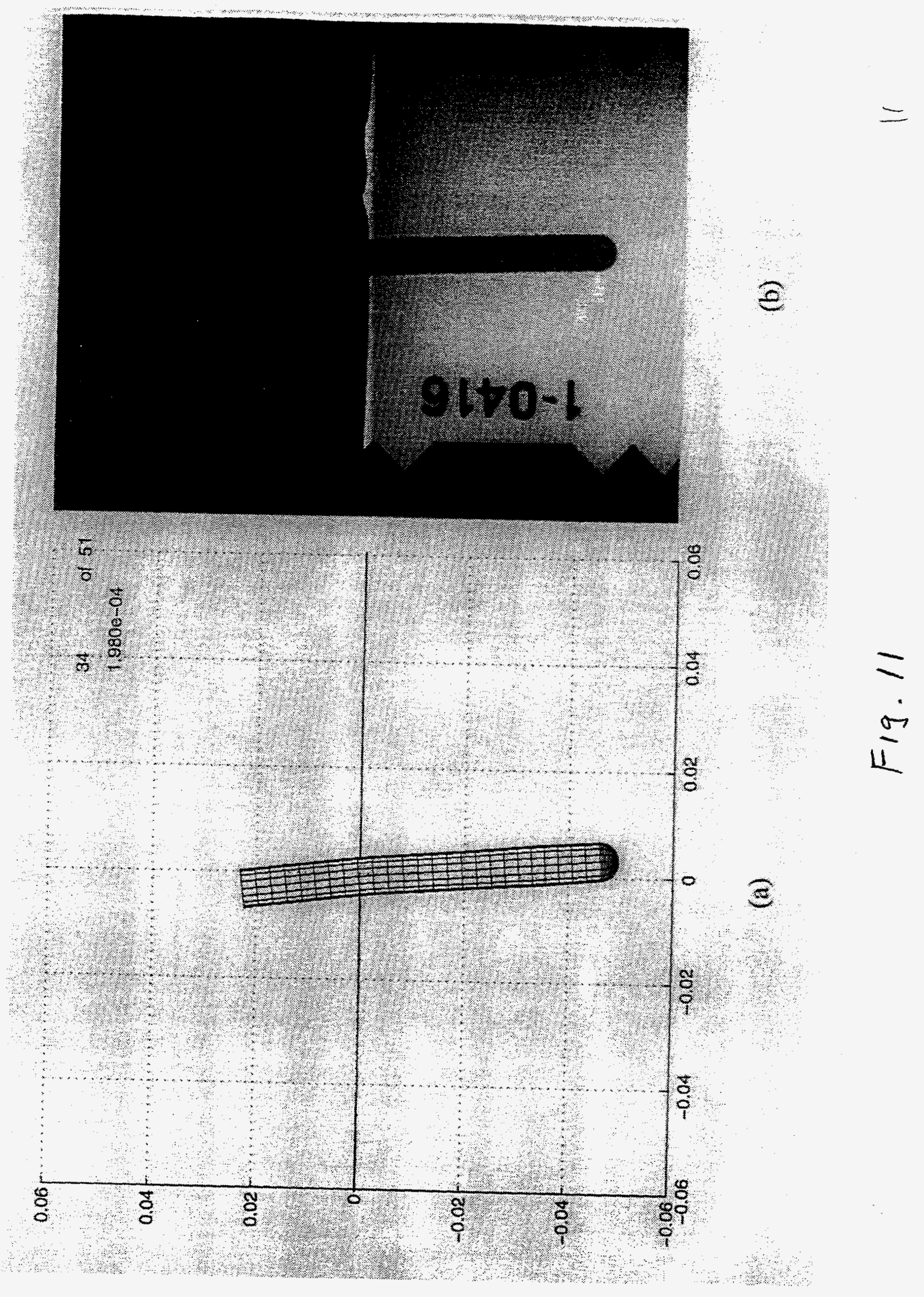




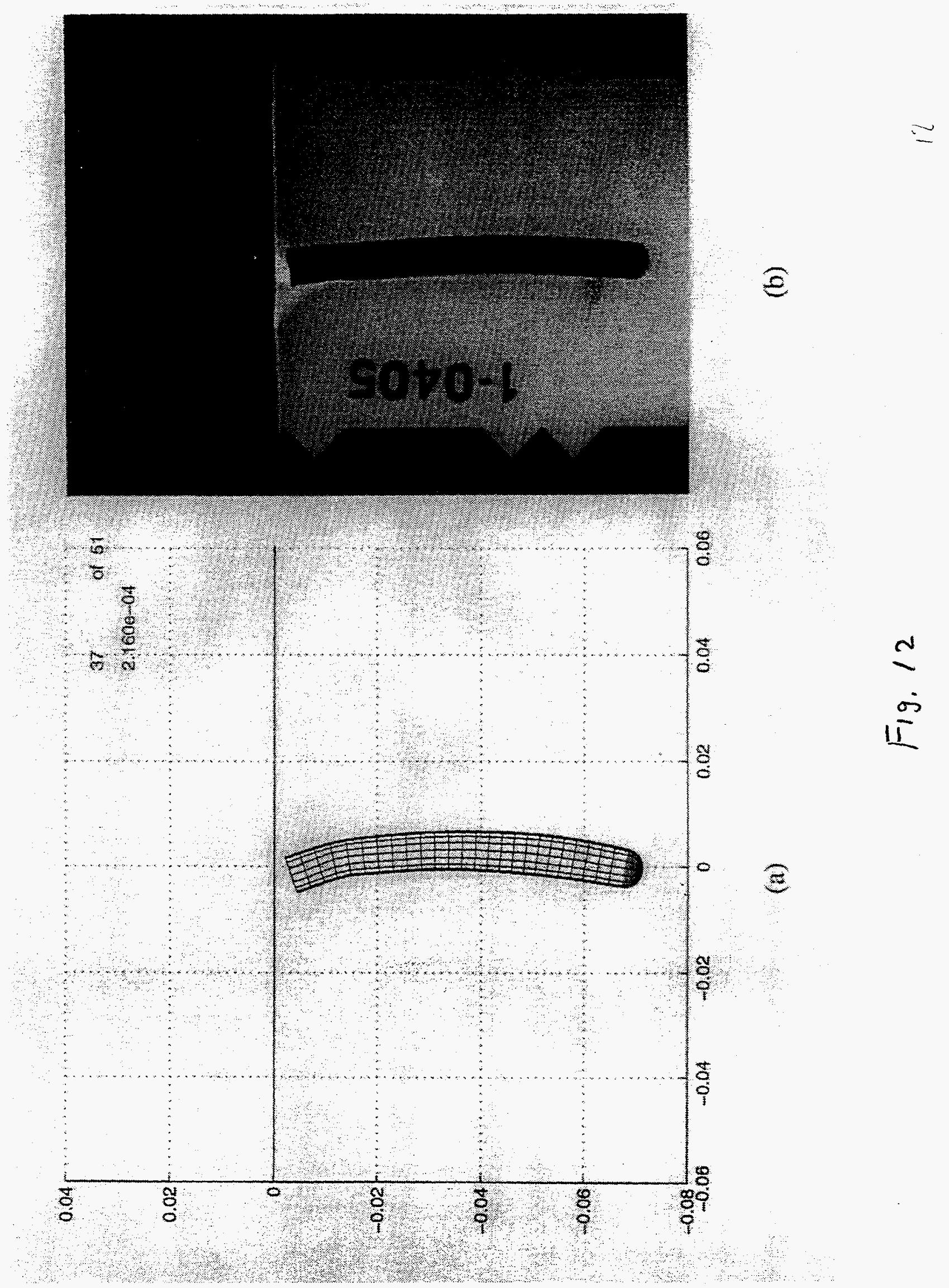




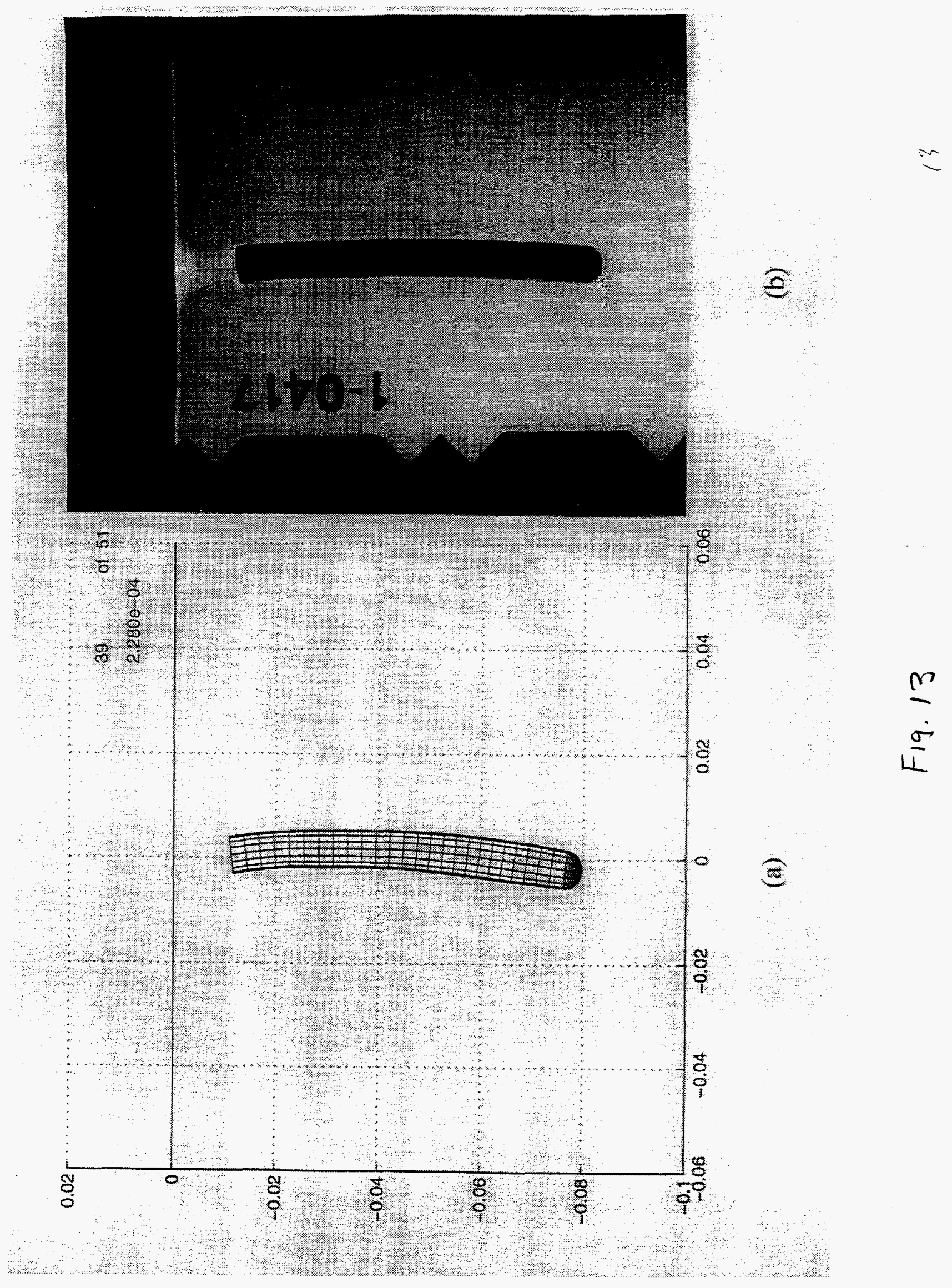




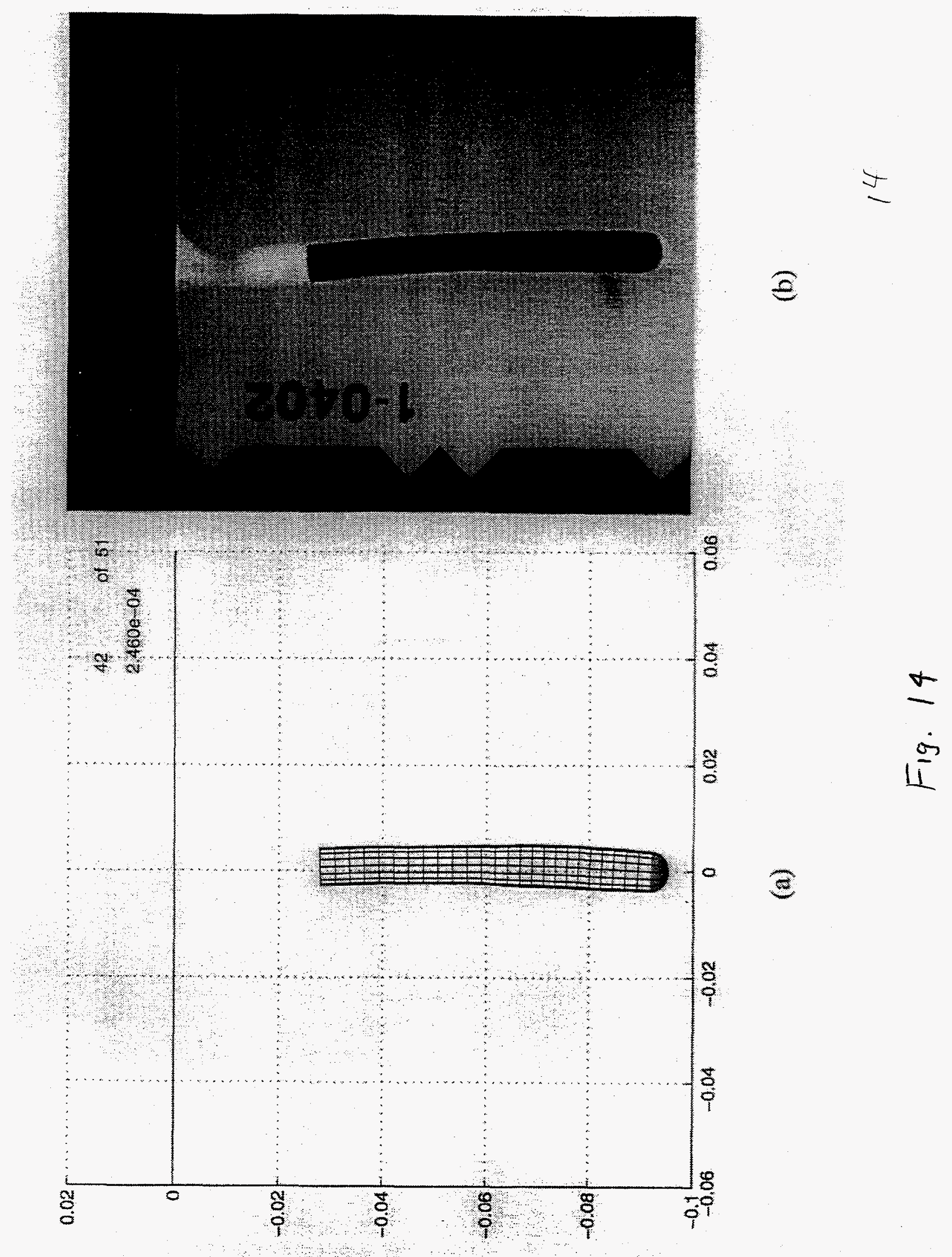




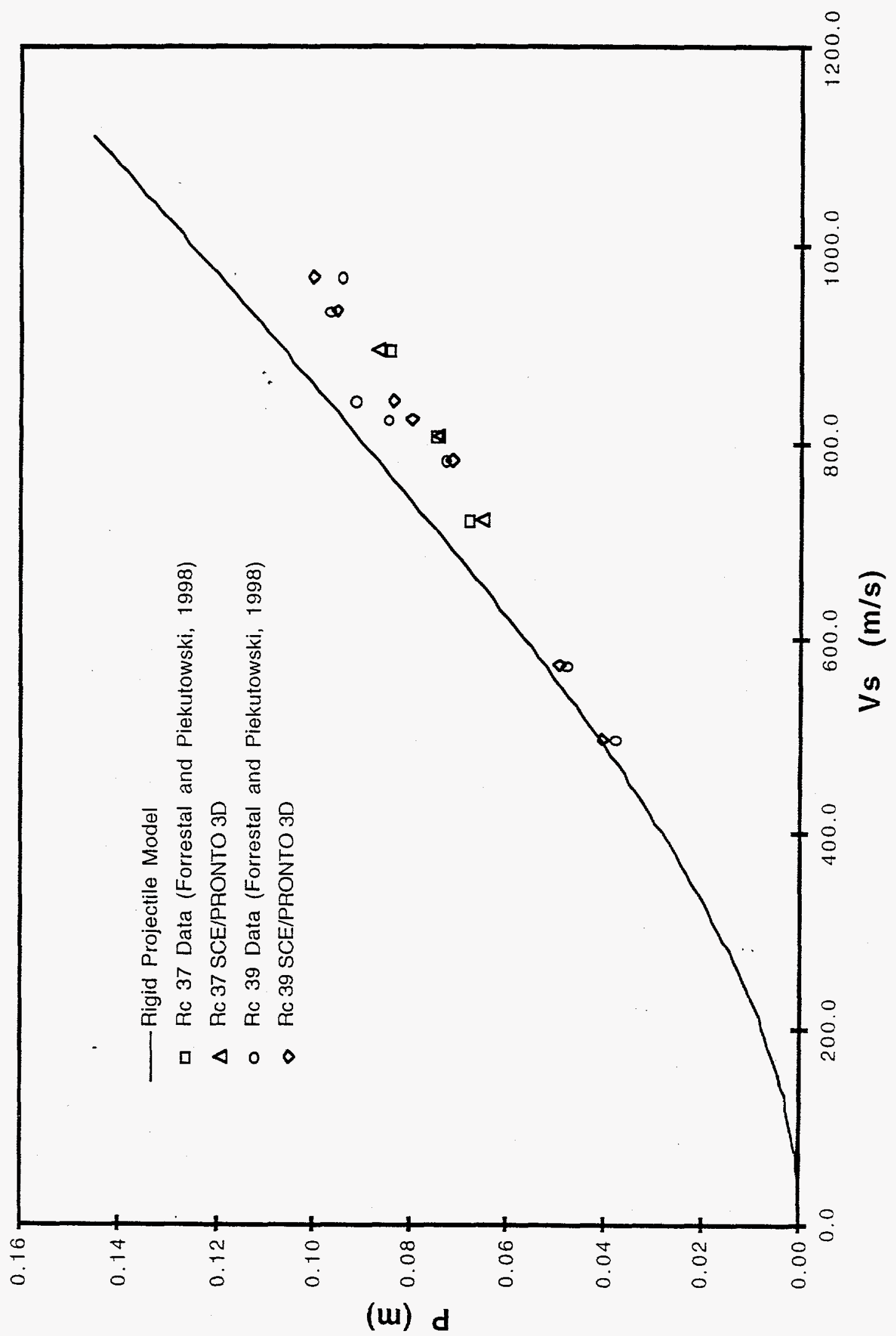

$\frac{b}{5}$ 